LETTERS TO THE EDITOR

\section{Multidrug resistant tuberculosis}

We read with interest the report by White and Moore-Gillon ${ }^{1}$ on the resource implications of multidrug resistant tuberculosis (MDRTB) in the UK. We studied the outcome of 44 HIV negative patients with MDR-TB admitted to two tertiary care tuberculosis units in the Netherlands between 1985 and $1998 . .^{23}$ Most (38 patients) had pulmonary tuberculosis. The mean admission period was 164 days and all patients received an individually tailored combination of antituberculosis drugs for a mean period of 608 days. We estimated the cost of treatment per patient to be US $\$ 60000$ which included admission fee, costs for outpatient visits, and the costs of drug provision. Although we did not include cost of toxicity monitoring and additional procedures, our costs compare favourably with those of White et al (mean $£ 60000$ ) and $\mathrm{Mahmoudi}^{4}$ (mean US $\$ 180$ 000).

In the Netherlands the number of patients with tuberculosis resistant to any antituberculous drugs is limited to $11 \%$, and only $0.6 \%$ of the bacilli are MDR. Between 1993 and 1997 only 43 cases of MDR-TB were identified, of which $28 \%$ had received previous treatment for tuberculosis (Index Tuberculosis 1998, Royal Netherlands Tuberculosis Association, The Hague, 2000). This suggests that transmission of MDR bacilli rather than inadequate treatment contributes to the resistance problem in the Netherlands.

In poor resource countries, directly observed short course chemotherapy of tuberculosis is generally recommended to prevent the occurrence of MDR-TB. We feel that new rapid molecular methods for detecting resistance should be developed to limit the period of potential (nosocomial and community) transmission of MDR bacilli and thus prevent the emergence of MDR-TB. Such tests should then be made available to poor resource countries at an affordable price.

W A GEERLIGS

Department of Internal Medicine, Groningen University Hospital, 9700 RB Groningen, the Netherlands

R VAN ALTENA

Tuberculosis Unit, Beatrixoord,

9750 RA Haren, the Netherlands

T S VAN DER WERF

Respiratory \& Intensive Care Unit,

Department of Internal Medicine,

Groningen University Hospital, 9700 RB Groningen, the Netherlands

Correspondence to: Dr T S van der Werf

1 White VCL, Moore-Gillon J. Resource implications of patients with multidrug resistan tuberculosis. Thorax 2000;55:962-3.

2 Geerligs WA, van Altena R, van der Werf TS Antituberculosis-drug resistance. $N$ Engl f Med 1998;339:1079-80.

3 Geerligs WA, van Altena R, de Lange WCM, et al. Multidrug-resisant tuberculosis: long-term treatment outcome in the Netherlands. Int $\mathcal{F}$ Tuberc Lung Dis 2000;4:758-64.

4 Mahmoudi A, Iseman MD. Pitfalls in the care of patients with tuberculosis. Common errors and their association with the acquisition of drug resistance. fAMA 1993;270:65-8.

\section{Cost of physiotherapy in CF}

Increasing survival is associated with increasing numbers of adults with cystic fibrosis $(\mathrm{CF})$. It is recognised that management at specialist CF units is associated with improved health outcomes. ${ }^{1}$ Assessment of the allocation of staff and resources to adults with $\mathrm{CF}$ and accurate costing of these services are essential to enable evaluation of the cost effectiveness of the existing CF services and prediction of future requirements. Global costs of care for young people with CF have been estimated, but studies of the cost of providing physiotherapy for a CF service are scarce. $^{23}$

The cost and utilisation of providing a physiotherapy service to inpatients with $\mathrm{CF}$ was determined from February to June 1999 (late summer, autumn and early winter). Using staff designation (pay level), time of physiotherapy (in 5 minute unit allotments), and after hour penalties incurred, comparison was made with actual funding for the service. At the time of the study the Adult CF Unit at the Prince Charles Hospital in Brisbane provided clinical care for 120 adults with CF from throughout Queensland, with patients travelling up to $1800 \mathrm{~km}$. Despite an active home intravenous antibiotic programme, many patients require admission for treatment of pulmonary exacerbations. Physiotherapy management included respiratory therapy, education, and exercise and was available to all inpatients with CF on a 24 hour basis when required. Outpatient and domiciliary physiotherapy service provision were excluded from this analysis.

During the 5 month study period (150 days) there were 102 inpatient admissions in 58 patients (mean length of stay 12.1 days). Two patients (with two admissions each) were inpatients for a total of 116 and 129 days, respectively, and two patients died during the study. In 5 months 1498 hours of physiotherapy were provided at a cost of $£ 13700$ (\$AUD38 000), equating to $£ 12$ (\$AUD32) per patient per day. This involved a mean of 9.9 hours of physiotherapy per day. This cost exceeded funding for the service by $28 \%$ ( $£ 630 /$ month). The total time of physiotherapy varied from 233 to 401 hours per month. The majority of the service was provided during normal working hours $(72.9 \%)$. Due to penalty wage rates for after hour's work, only $58.5 \%$ of the total cost was provided during normal working hours. The weekend and public holiday physiotherapy used $22.8 \%$ and $3.3 \%$ of the time but accounted for $33.6 \%$ and $6.8 \%$ of cost, respectively. Physiotherapy care provided during weekday evenings amounted to $1 \%$ of total time and total cost.

This analysis shows that the cost of inpatient physiotherapy in a tertiary referral service is $£ 92$ (\$AUD253) per day or $£ 12$ per patient per day. Provision of a service outside normal working hours accounts for a significant proportion of the cost of this service. Regular analysis of time utilisation is required to determine if adequate staffing levels and funding are available to meet the challenge of an increasing population of adults with CF.

K STALLARD H SEALE S C BELL Adult Cystic Fibrosis Unit, The Prince Charles Hospital, Chermside, Queensland 4032, Australia Scott_Bell@health.qld.gov.au
1 Mahadeva R, Webb K, Westerbeek RC, et al. Clinical outcome in relation to care in centres specialising in cystic fibrosis: study. BM 1998;316:1771-5.

Robson M, Abbott J, Webb K, et al. A cost description of an adult cystic fibrosis unit and cost analyses of different categories of patients. Thorax 1992;47:684-9.

3 Wildhagen MF, Verheij JBGM, Henk BM, et al. Cost of care of patients with cystic fibrosis in the Netherlands in 1990-1. Thorax 1996;51: 298-301.

\section{Systemic effects of inhaled steroids}

The recent article by Harrison and colleagues has limitations which were not adequately addressed. ${ }^{1}$ It was perhaps hardly surprising to find no differences in plasma budesonide concentrations between normal and asthmatic subjects due to the higher levels and a relatively insensitive assay compared with fluticasone.

The respective dry powder inhaler devices for each drug differ markedly in their fine particle dose delivery which will determine peripheral lung deposition and, in turn, systemic absorption. The fine particle dose expressed as a percentage of the nominal dose for fluticasone Accuhaler (Diskus) is 12\% compared with $40 \%$ for budesonide Turbuhaler. ${ }^{2}$ Moreover, there is a much higher proportion of coarse particles from the Accuhaler than from the Turbuhaler. ${ }^{3}$ The study was therefore biased towards showing greater attenuation of peripheral lung absorption with fluticasone Accuhaler in asthmatic subjects.

The authors state that they are unaware of any previous direct comparisons of the effects of fluticasone and budesonide on osteocalcin concentrations. In adult asthmatic subjects steady state dosing for 12 days showed greater percentage suppression with fluticasone than with budesonide of 08.00 hour plasma cortisol levels compared with placebo $(48 \%$ v 20\%) which was mirrored by suppression of 08.00 hour serum osteocalcin levels $(37 \%$ v $12 \%) .{ }^{4}$ This would not be consistent with the hypothesis of Harrison et al that fluticasone and budesonide may have differential effects on the HPA axis and bone metabolism

Finally, it is worth noting that a metaanalysis of 21 studies evaluating dose related suppression of urinary cortisol levels showed a 4.3-fold $(p<0.001)$ difference in slope when comparing fluticasone and budesonide. ${ }^{5}$

B J LIPWORTH Asthma and Allergy Research Group, Department of Clinical Pharmacology \& Therapeutics, Ninewells Hospital and Medical School, University of Dundee, Dundee DD1 9SY, UK b.j.lipworth@dundee.ac.uk

1 Harrison TW, Wisniewski A, Honour J, et al. Comparison of the systemic effects of fluticasone propionate and budesonide given by dry powder inhaler in healthy and asthmatic subjects. Thorax 2001;56:186-91.

2 Olsson B. Aerosol particle generation from drypowder inhalers: can they equal pressurized metered dose inhalers? F Aerosol Med 1995;8: 513-9.

3 Bisgaard H, Klug B, Sumby BS, et al. Fine particle mass from the Diskus inhaler and Turbuhaler inhaler in children with asthma. Eur Respir f 1998;11:1111-5.

4 Lipworth BJ, Clark DJ. High dose inhaled steroids in asthmatic children. Lancet 1996;348 820

5 Lipworth BJ. Systemic adverse effects of inhaled corticosteroid therapy: a systematic review and meta-analysis. Arch Intern Med 1999;159:941 55. 
AUTHORS' REPLY We thank Professor Lipworth for his interest in our paper. The main hypothesis being tested was a comparison of the total cortisol metabolite levels after 7 days of treatment with fluticasone propionate and budesonide between healthy and asthmatic subjects. Although we were interested in the plasma levels of the two drugs, limitations in the assays available prevented us from studying this in more detail. Brutsche et al have, however, also shown markedly lower fluticasone plasma levels in subjects with asthma compared with healthy controls, and we now have data confirming that budesonide plasma levels are identical in healthy and asthmatic subjects.

We accept that part of the explanation for the difference between fluticasone and budesonide may have resulted from differences in the inhalers used. We used dry powder inhalers because we wanted to reduce the effects of inhaler technique and because dry powder inhalers had been used in a number of studies comparing fluticasone and budesonide in healthy subjects. ${ }^{2-4}$ It is also worth noting that Brutsche et al ${ }^{1}$ studied metered dose inhalers with a large volume spacer and produced similar results to ours.

We are grateful to Professor Lipworth for bringing our attention to his letter reporting a study in subjects with mild asthma. ${ }^{5}$ This appears to be the same as a later publication that we had referenced in which the osteocalcin data were omitted. ${ }^{6}$ The reduction in osteocalcin concentrations with budesonide but not fluticasone at microgram equivalent doses was an unexpected finding and we did state that confirmation of this finding was required.

Finally, we have major reservations about the meta-analysis published by Lipworth, not only because it combined studies performed in healthy and asthmatic subjects but because it included a number of studies which did not compare fluticasone and budesonide, so it does not satisfy the methodology for a metaanalysis.

T HARRISON A TATTERSFIELD Division of Respiratory Medicine, City Hospital,

Nottingham NG5 1PB, UK tharris2@ncht.org.uk

1 Brutsche $\mathrm{MH}$, Brutsche IC, Munawar M, et al. Comparison of pharmacokinetics and systemic effects of inhaled fluticasone propionate in patients with asthma and healthy volunteers: patients with asthma and healthy volunteers: a
randomised crossover study. Lancet 2000;356:556-61.

2 Grove A, Allam C, McFarlane LC, et al. A com parison of the systemic bioactivity of inhaled budesonide and fluticasone propionate in normal subjects. Br f Clin Pharmacol 1994;38: 527-32

3 Grahnén A, Jansson B, Brundin RM, et al. A dose-response study comparing suppression of plasma cortisol induced by fluticasone propiplasma cortisol induced by fluticasone propiTurbuhaler. Eur $\mathcal{f}$ Clin Pharmacol 1997;52: 261-7.

4 Lönnebo A, Grahnén A, Jansson B, et al. An assessment of the systemic effects of single and repeated doses of inhaled fluticasone propionate and inhaled budesonide in healthy volunteers. Eur F Clin Pharmacol 1996;49:459-63.

5 Lipwoth BJ, Clark DJ. High dose inhaled steroids in asthmatic children. Lancet 1996; 348:820.

6 Clark DJ, Lipworth BJ. Adrenal suppression with chronic dosing of fluticasone propionate compared with budesonide in adult asthmatic compared with budesonide in

7 Lipworth BJ. Systemic adverse effects of inhaled corticosteroid therapy: a systematic review and meta-analysis. Arch Intern Med 1999;159:941 55.
The study by Harrison and colleagues ${ }^{1}$ suggests that inhaled fluticasone in a dose of $1500 \mu \mathrm{g} /$ day can cause pituitary suppression as measured by urinary total cortisol metabolites (TCM) in healthy subjects compared with asthmatics, but that budesonide in a dose of $1600 \mu \mathrm{g} /$ day does not. For fluticasone, the mean difference between healthy and asthmatic TCM after 7 days treatment with fluticasone was significant but the same comparison for budesonide was not. The confidence interval for the mean difference in TCM between the healthy and asthmatic subjects given budesonide was positive but with a $\mathrm{p}$ value of 0.2 . Is this explained by the omission of a sign?

However, when change from baseline is examined in healthy subjects, both drugs suppress TCM and the difference between them was not significant. If equipotent dosages of $750 \mu \mathrm{g}$ fluticasone/day and $1600 \mu \mathrm{g}$ budesonide/day had been given, would the urinary TCM be significantly different for healthy subjects? This is of practical importance if inhaled corticosteroids are considered for treating patients who do not have asthma. Children with isolated persistent cough, which is not asthma, ${ }^{2}$ are often prescribed inhaled corticosteroids. ${ }^{3}$ Adrenal crises in patients believed to have asthma who have been prescribed inhaled steroids must be examined carefully.

This paper and others which have reported systemic effects of inhaled steroids in healthy subjects $^{4-6}$ should caution against the indiscriminate use of these drugs in patients who do not have asthma.

S A MCKENZIE Fielden House, Royal London Hospital London E1 1BB, UK mckenzie@rhtch.demon.co.uk

1 Harrison TW, Wisniewski A, Honour J, et al. Comparison of the systemic effects of fluticasone propionate and budesonide given by dry powder inhaler in healthy and asthmatic subjects. Thorax 2001;56:186-91.

2 Chang $\mathrm{AB}$. Isolated cough: probably not asthma. Arch Dis Child 1999;80:211-3.

3 Picciotto A, Hubbard M, Sturdy $\mathrm{P}$, et al. Prescribing for persistent cough in children. Respir Med 1998;92:638-41.

4 Donnelly R, Williams KM, Baker AB, et al. Effects of budesonide and fluticasone on 24-hour plasma cortisol. A dose-response study. Am 7 Respir Crit Care Med 1997;156: study. $A$ - 1746

5 Boorsma M, Andersson N, Larsson P, et al. Assessment of the relative systemic potency of inhaled fluticasone and budesonide. Eur Respir f 1996;9:1427-32.

6 Grahnen A, Jansson B, Brundin RM, et al. A dose-response study comparing suppression of plasma cortisol induced by fluticasone propionate from Diskhaler and budesonide from Turbuhaler. Eur $\mathcal{f}$ Clin Pharmacol 1997;52: 261-7.

AUTHORS' REPLY We thank Dr McKenzie for her interest in our paper. The confidence interval for the mean difference in TCM between budesonide in healthy and asthmatic subjects should be -484 to 2904 as in the abstract.

We agree that the systemic effects of some inhaled corticosteroids may be greater in subjects without asthma than in those with asthma and airflow obstruction, and that caution is needed if inhaled corticosteroids are prescribed for such patients. Our study does not allow a comparison of $750 \mu \mathrm{g}$ fluticasone propionate and $1600 \mu \mathrm{g}$ budesonide in healthy subjects. Whether these doses given by their respective dry powder inhalers are truly equally effective in patients who do not have asthma is also unknown, however.

T HARRISON A TATTERSFIELD Division of Respiratory Medicine, City Hospital, Nottingham NG5 1PB, UK tharris2@ncht.org.uk

\section{Pulmonary infiltrates in non-HIV patients}

We read with interest the article by Rano et al in the May edition of Thorax. ${ }^{1}$ This group showed that, by using non-invasive methods (blood cultures, sputum cultures, nasopharyngeal washes and tracheobronchial aspirates), they were able to make a positive diagnosis in $41 \%$ of 200 non-HIV immunocompromised patients with pulmonary infiltrates.

We have looked at a similar group of patients treated in the Leukaemia and Lymphoma Units at the Royal Marsden Hospital who needed investigation for pulmonary infiltrates ${ }^{2}$ and found a low diagnostic yield from bronchoscopy with neither a positive result $(36 \%)$ nor a change in management (28\%) making any impact on survival. Like Rano et al, we are therefore keen to explore the use of non-invasive investigations.

From our literature review we found many groups advocating the use of high resolution CT scanning (HRCT) of the chest. It has found particular use in those patients with a normal chest radiograph but respiratory symptoms and fever, ${ }^{3}$ having a negative predictive value after bone marrow transplantation of $97 \%$. The HRCT scan has characteristic appearances in aspergillosis, ${ }^{4}$ Pneumocystis carinii pneumonia (PCP), ${ }^{5}$ and cytomegalovirus (CMV) infection. ${ }^{6}$ One group has compared HRCT and bronchoalveolar lavage (BAL) in the diagnosis of fungal pneumonia and found the former to be superior. ${ }^{7}$ From these data we proposed that such characteristic appearances on CT scanning could obviate the need for bronchoscopy.

In the paper by Rano et al 30 isolates (15\%) were of $A$ fumigatus and four (2\%) were of PCP. Do the authors feel that these patients might have been diagnosed by HRCT scanning and thus have avoided bronchoscopy altogether?

Antifungal treatment was only instigated after 4-5 days if there was no improvement or positive microbiology. With such a policy the mortality rate in those with Aspergillus infections was $67 \%$. Other groups recommend early introduction of antifungal treatment due to its high prevalence, particularly in haematological malignancies. ${ }^{7}$ In the light of their results and the potential of early HRCT scanning, have the group changed their practice to include early use of antifungal treatment?

$$
\begin{array}{r}
\text { P MURRAY } \\
\text { M O'BRIEN } \\
\text { Lung Unit, } \\
\text { Royal Marsden Hospital, } \\
\text { Downs Road, } \\
\text { Sutton, Surrey SM2 5PT, UK }
\end{array}
$$

1 Rano A, Agusti C, Jimenez P, et al. Pulmonary infiltrates in non-HIV immunocompromised patients: a diagnostic approach using noninvasive and bronchoscopic procedures. Thorax 2001;56:379-87. 
2 Murray PV, O'Brien MER, Padhani AR, et al. Use of first line bronchoalveolar lavage in the immunosuppressed oncology patient. Bone Marrow Transplantation 2001;27:967-7

3 Heussel CP, Kauczor H-U, Heussel G, et al. Pneumonia in febrile neutropaenic patients and in bone marrow and blood stem-cell transplant recipients: use of high-resolution computed tomography. F Clin Oncol 1999;17:796805.

4 Hruban RH, Meziane MA, Zerhouni EA, et al. Radiologic-pathologic correlation of the CT halo sign in invasive pulmonary aspergillosis. $\mathcal{F}$ halo sign in invasive pulmonary asper
Comput Assist Tomogr 1987;11:534-6.

5 Hartman TE, Primack SL, Muller NL, et al. Hartman TE, Primack SL, Muller NL, et al.
Diagnosis of thoracic complications in AIDS Accuracy of CT. Am f Roentgenol 1994;162 547-53.

6 Kang EY, Patz EF Jr, Muller NL. Cytomegalovirus pneumonia in transplant patients: CT findings. 7 Comput Assist Tomogr 1996;20:2959.

7 Von Eiff M, Zuhlsdorf M, Roos N, et al. Pulmonary fungal infections in patients with haematological malignancies: diagnostic approaches. Ann Haemol 1995;70:135-41.

AUTHORS' REPLY We appreciate the valuable comments by Drs Murray and O'Brien regarding our study on immunocompromised patients. In our study the diagnostic yield of non-invasive methods was $41 \%{ }^{1}$ The good results obtained with these techniques, as well as their availability and relatively low cost, make them very useful in the clinical management of immunocompromised patients. In this sense, HRCT scanning, as Drs Murray and O'Brien point out, has a demonstrated role in the diagnosis of some pulmonary complications, particularly Aspergillus pneumonia, and can be included in the diagnostic strategies of non-invasive diagnostic techniques. Whether or not an HRCT scan might facilitate the early start of antifungal treatment and improve the mortality from Aspergillus pneumonia will need to be evaluated in properly designed studies.

Although non-invasive techniques must be considered as a first step in the clinical management of immunocompromised patients, their use cannot justify any delay in performing a bronchoscopic exploration. In this sense, and contrary to the experience reported by Drs Murray and O'Brien, the systematic use of endoscopic techniques allowed us to increase the diagnostic yield up to $81 \%$. We believe that obtaining an early diagnosis in immunocompromised patients is of paramount importance. In fact, the low diagnostic yield of the 25 bronchoscopies performed in the series by Murray et al and the lack of impact on survival, also reported by other groups, ${ }^{2-4}$ may well be due to the fact that the endoscopic techniques are performed too late in the evolution of the disease when the possibilities of influencing the outcome are very few.

Replacing bronchoscopic techniques by HRCT scanning carries the risk of misdiagnosing polymicrobial lung infectious and non-infectious pulmonary complications in which bronchoalveolar lavage and bronchial aspirates have a known diagnostic role. Remarkably, in 11 of the 15 polymicrobial infections reported in our series, ${ }^{1}$ both Aspergillus and/or cytomegalovirus (CMV) were involved. In these cases the use of HRCT scanning instead of bronchoscopy would probably have missed one of the other co-existent pathogens. We therefore do not believe that HRCT scanning of the chest can replace bronchoscopy in the clinical management of immunocompromised patients with pulmonary infiltrates.

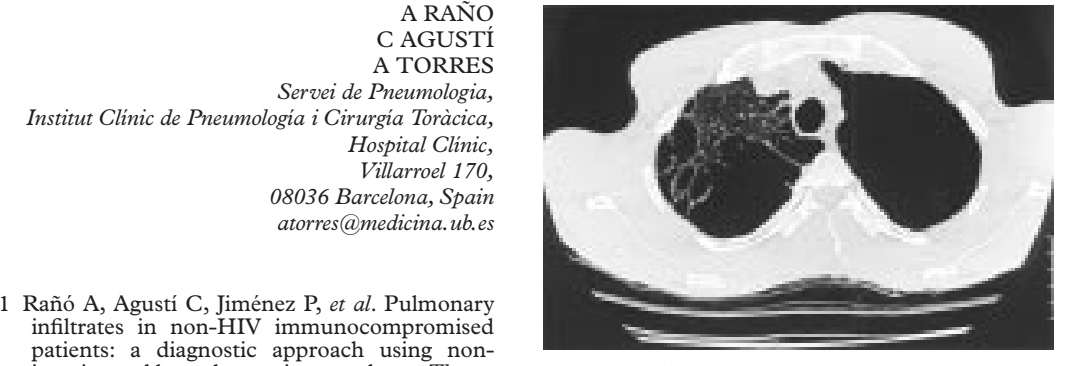
patients: a diagnostic approach using noninvasive and bronchoscopic procedures. Thorax 2001;56:379-87.

2 Murray PV, O'Brien MER, Padhani AR, et al. Use of first line bronchoalveolar lavage in the immunosupressed oncology patient. Bone Marrow Transplant 2001;27:967-71.

3 Dunagan DP, Baker AM, Hurd DD, et al. Bronchoscopic evaluation of pulmonary infiltrates choscopic evaluation of pulmonary infiltrate following bone marrow transplantation. Chest 1997,111:135-41.

White P, Bonacum JT, Miller CB. Utility of fiberoptic bronchoscopy in bone marrow transplant patients. Bone Marrow Transplant 1997; 20:681-7.

\section{Severe bullous emphysema associated with cocaine smoking}

Pulmonary emphysema is characterised by permanent enlargement of airspaces distal to the terminal bronchiole accompanied by destruction of alveolar walls. The loss of elastic tissue contained in the interalveolar septa is caused by an imbalance between proteinase and antiproteinase activity, most commonly caused by cigarette smoking. Congenital deficiency of $\alpha_{1}$-antitrypsin, the most well known antiproteinase, is an important risk factor for the development of premature emphysema. In addition, various other causes have been reported including intravenous drug abuse ${ }^{12}$ particularly Ritalin. ${ }^{3}$ More recently, Johnson et $a l^{4}$ reported four cases of bullous emphysema associated with marijuana smoking. We want to report an additional case of severe premature bullous emphysema in a man with a longstanding history of cocaine smoking. To the best of our knowledge, this relationship has only once been reported in the Spanish medical literature. ${ }^{5}$
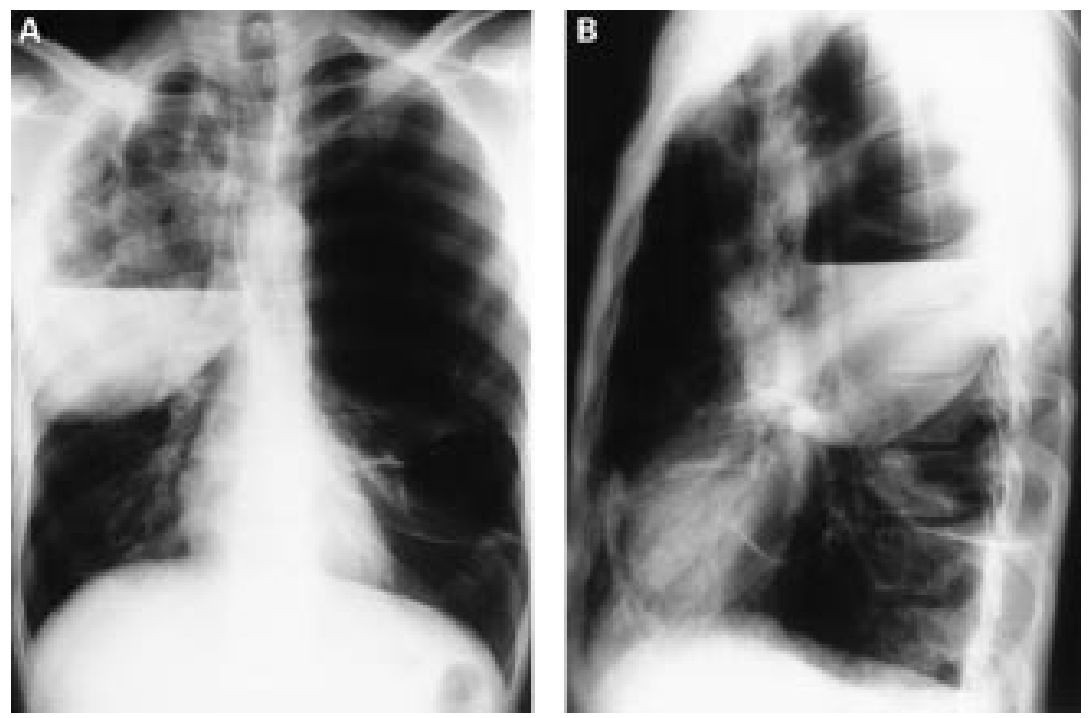

Figure 1 Chest radiograph on admission showing severe bilateral bullous emphysema with a large air-fluid collection in the right lung suggestive of pulmonary abscess formation.

A 40 year old man was admitted with progressive dyspnoea, cough, and fever. According to his relatives he had been smoking cocaine (so called "free basing") for the past 17 years. A reliable history of tobacco smoking could not be obtained because of his respiratory distress and poor level of consciousness. His medical history consisted of recurrent respiratory tract infections. Chest 
radiographs and computed tomographic scans showed impressive bilateral bullous emphysema with a large air-fluid collection in the right lung, suggesting pulmonary abscess formation (figs 1, 2, 3). Because of progressive respiratory failure he was intubated and mechanically ventilated. Further treatment consisted of intravenous broad spectrum antibiotics (clindamycin and ceftazidime followed by amoxicillin-clavulanic acid) and chest tube drainage because of ventilator associated pneumothorax. The patient eventually died of treatment resistant respiratory failure as a result of pneumonia in the scarce residual pulmonary tissue. Sputum cultures yielded Enterobacter cloacae and Streptococcus species. HIV infection was excluded serologically. The definitive diagnosis of cocaine induced pulmonary emphysema was established after the concentration of $\alpha_{1}$ antitrypsin was found to be within the normal range.

Besides congenital $\alpha_{1}$-antitrypsin deficiency, cocaine smoking should be considered as a possible cause of severe premature bullous emphysema. Abscess formation and rapidly progressive respiratory failure may complicate this condition.

J M VAN DER KLOOSTER A F GROOTENDORST Department of Intensive Care Medicine, Medisch Centrum Rijnmond-Zuid, Olympiaweg 350, 3078 HT Rotterdam, Netherland jmvanderklooster@planet.nl

1 Goldstein DS, Karpel JP, Appel D, et al. Bullous pulmonary damage in users of intravenous drugs. Chest 1986:89:266-9.

2 Weisbrod GL, Rahman M, Chamberlain D, et al. Precocious emphysema in intravenous drug al. Precocious emphysema in intravenous d.

3 Schmidt RA, Glenny RW, Godwin JD, et al. Panlobular emphysema in young intravenous Ritalin abusers. Am Rev Respir Dis 1991;143: Ritalin abu-56.

4 Johnson MK, Smith RP, Morrison D, et al. Large lung bullae in marijuana smokers. Thorax 2000;55:340-2

5 Fullana Monllor J, García Bermejo PA, Pellicer Ciscar C. Enfisema bullosa en fumadora de cocaína. Arch Bronconeumol 1998;34:514.

\section{Side effects of antituberculous treatment}

Combined antimycobacterial chemotherapy has been shown to be very effective in the treatment of Mycobacterium tuberculosis hominis $(\mathrm{MTH})$ pulmonary infections with a cure rate of $>85 \%$ for short term (6 month) courses. ${ }^{1}$ Recent WHO initiatives have been launched and are aimed at eradicating pulmonary tuberculosis by intensive adoption of directly observed treatment (DOT) strategies in countries in which the incidence is high.

A new drug formulation has recently been produced which provides the three main first line drugs in the same tablet in a fixed ratio (rifampin (RIF) $120 \mathrm{mg}$, isoniazid (INH) $50 \mathrm{mg}$, and pyrazinamide (PZM) $300 \mathrm{mg}$ ). ${ }^{2}$ This formulation is likely to be extremely useful, particularly in developing countries where it can provide reliable simultaneous administration of all the drugs needed on bi-weekly or tri-weekly DOT programmes. ${ }^{3}$ However, it is not intended to substitute any (or all) of the single components in countries where they are already available and marketed.

In a recent WHO report, of all the industrialised European countries, Italy reported the highest prevalence of multidrug resistance among previously treated cases of tuberculosis $(33.9 \%, 95 \%$ CI 25.7 to 42.7$)$, with any drug resistance accounting for up to $60.6 \%$ of the strains. ${ }^{4}$ In addition, there was a high prevalence of resistance in new cases of tuberculosis with $12.3 \%$ resistance to any drug. ${ }^{4}$

In Italy the distribution and marketing of PZM ceased as a single drug formulation between 15 June 2000 and early 2001. This abrupt policy change temporarily introduced a new and interesting challenge to the treatment of $\mathrm{MTH}$, and possibly increased risks of toxicity and decreased treatment efficiency for some patients.

Over the last 2 years we have treated 26 patients with pulmonary tuberculosis using the standard four drug regimens administered as single drugs and have recorded a relatively high rate of hepatotoxicity $(35 \%)$ compared with previous North American and European analyses (11\%). ${ }^{15}$ In eight of the nine patients with hepatotoxicity the substitution of $\mathrm{INH}$ led to normalisation of liver function. This incidence of side effects approaches the cumulative incidence of side effects $(26 \%)$ reported in a European study of similar design on 519 patients of similar mean age.

In our 26 patients we estimated that, if a fixed dose formulation had been used to maintain the dose of RIF at $10 \mathrm{mg} / \mathrm{kg} /$ day, a significantly increased dose of PZM (not correlated to the one that was actually given) would have been administered. Thus, it is reasonable to suggest that the already high rate of toxicity could increase in incidence and severity when PZM is administered daily as a fixed dose formulation. When considered in the context of the unavailability of PZM single drug formulations, two additional considerations are warranted.

Firstly, there is a limited choice of first line regimens which exclude INH for patients with INH related hepatotoxicity (for example, RIF+STM+EMB but not $\mathrm{RIF}+\mathrm{PZM}+\mathrm{STM})$. Side effects in hospital treated patients usually lead to withdrawal of one of the basic drugs and replacement by other drugs such as ethambutol or streptomycin. This may lead to more prolonged treatment and to decreased adherence. ${ }^{5}$ However, these negative consequences would be considerably enhanced if single drug formulations of PZM are not available since withdrawal of at least two first line drugs would be needed (PZM + INH).

Secondly, the treatment of patients with chronic tuberculosis who are infected with the most frequent INH or RIF resistant MTH $\left(43.3 \%\right.$ and $44.9 \%$, respectively) ${ }^{4}$ or with multidrug resistant MTH could lead to the drug being acquired from abroad at high cost, and sometimes to interruptions in the supply with dangerous consequences for the patient's health. In fact, most tuberculosis units in our area acquired PZM as a single drug formulation from neighbouring countries during the time when it was not available.

Thus, available data do not support the use of fixed dose formulations as the only treatment choice in developed countries. This could be particularly dangerous where there is a high prevalence of multiple drug resistant $\mathrm{MTH}$, including developing countries.

A DE MARIA
M BERARDI
P DIGNETTI
L FERRERA
L VIASSOLO
G W CANONICA
Department Internal Medicine,
University of Genoa,
Genoa 16132, Italy
de-maria@unige.it

1 Coombs DL, O'Brien RJ, Geiter LJ. USPHS tuberculosis short-course chemotherapy trial 21: effectiveness, toxicity and acceptability. Ann Intern Med 1990;112:397-406.

2 WHO/OMS. Fixed-dose combination tablets for the treatment of tuberculosis. Report of an the treatment of tuberculosis. Report of an
informal meeting held in Geneva, 27 April 1999. WHO/CDS/CPC/TB/99.267: 1-45.

3 Gilbert DN, Moellering RC, Sande MA. Clinical approach to initial choice of antimicrobial therapy. In: The Sanford guide to antimicrobial therapy 200079-81. Hyde Park, VT, USA: Antimicrobial Therapy Inc, 1:16.

4 Espinal MA, Laszlo A, Simonsen L, et al. Global trends in resistance to antitubeculous drugs. $N$ Engl F Med 2001;344:1294-303.

5 Schaberg T, Rebhan K, Lode H. Risk factors for side-effects of isoniazid, rifampin and pyrazinamide in patients hospitalized for pulmonary tuberculosis. Eur Respir F 1996;9:2026-30.

\section{NOTICE}

\section{Basic and Clinical Allergy 2002}

"Basic and Clinical Allergy 2002" will be held at the National Heart \& Lung Institute, Faculty of Medicine, Imperial College, London on 18-22 March 2002. Main topics include: Basic cellular mechanisms and their application in allergic disease; Allergic rhinitis; Indoor allergens; Allergen specific immunotherapy and $\mathrm{T}$ cell tolerance; Asthma (aetiology and pathogenesis); Treatment of asthma. CPD/CME approval pending (2001 course maximum 23.5 credits). Further details from the Short Courses Office, Education Centre, Faculty of Medicine, Imperial College, National Heart \& Lung Institute, Dovehouse Street, London SW3 6LY, UK. Telephone +44 (0) 20 7351 8172. Fax +44 (0)20 73518246. Email: shortcourses.nhli@ic.ac.uk; website: www.med.ic.ac.uk/divisions/47a/mtgs.htm. 